\title{
The Heats of Combustion of Polytetrafluoroethylene (Teflon) and Graphite in Elemental Fluorine*
}

\author{
E. S. Domalski and G. T. Armstrong \\ Institute for Basic Standards, National Bureau of Standards, Waśhington, D.C. 20234
}

(December 16, 1966)

\begin{abstract}
Bomb calorimetric measurements are reported for the combustion in fluorine of polytetrafluoroethylene (Teflon) and graphite-polytetrafluoroethylene mixtures. Mass spectrometric examination of the product gases showed $\mathrm{CF}_{4}$ to be the only major product with $\mathrm{C}_{2} \mathrm{~F}_{6}(\mathrm{~g})$ present in only very small amounts. The completeness of combustion of the graphite was determined by chemical analysis of combustion residues and found to range from 97 to better than 99 percent. From the combustion data, the heats of formation $\Delta H_{f 298}^{\circ}\left[\mathrm{CF}_{4}(\mathrm{~g})\right]$ and $\Delta H_{f 298}^{\circ}\left[\mathrm{C}_{2} \mathrm{~F}_{4}\right.$ (solid polymer)] were determined to be -222.87 $\pm 0.38 \mathrm{kcal} \mathrm{mol}^{-1}$ and $-197.82 \pm 0.39 \mathrm{kcal}\left(\mathrm{gfw} \mathrm{C}_{2} \mathrm{~F}_{4}\right)^{-1}$, respectively. The uncertainties are estimates of the overall experimental errors.

A previously reported value for the heat of formation of $\mathrm{AlF}_{3}(\mathrm{c})$ is adjusted to be consistent with the present work. An evaluation of other data on $\mathrm{CF}_{4}$ is presented. The heat of formation of $\mathrm{CF}_{4}(\mathrm{~g})$ is combined with other work to derive the heats of formation of $\mathrm{HF}$ solutions at three specific concentrations.
\end{abstract}

Key Words: Aluminum fluoride, carbon tetrafluoride, fluorine, fluorine bomb calorimetry, graphite, heat of combustion, heat of formation, hydrogen fluoride aqueous, Teflon.

\section{Introduction}

The desirability of obtaining an accurate value for the heat of formation of carbon tetrafluoride is suggested by the number of efforts that have been directed toward obtaining this datum over the past thirty years, and the difficulty in obtaining it is indicated by the wide variation of the data. Von Wartenberg and Schütte $[1]^{1}$ reacted fluorine with carbon (Norite) in a flow calorimeter and calculated the heat of formation of carbon tetrafluoride to be $-162 \pm 2 \mathrm{kcal} \mathrm{mol}^{-1}$. Ruff and Bretschneider [2] later showed that the presence of fluorocarbons in the product gases necessitated a correction which changed this value for $\mathrm{CF}_{4}(\mathrm{~g})$ to $-183.5 \mathrm{kcal} \mathrm{mol}^{-1}$. Scott, Good, and Waddington $[3,4]$ determined the heat of combustion of polytetrafluoroethylene (Teflon) in an oxygen bomb, and calculated the heat of formation of $\mathrm{CF}_{4}(\mathrm{~g})$ to be -218.3 kcal mol ${ }^{-1}$. Jessup, McCoskey, and Nelson [5] reacted methane with fluorine in a flow calorimeter at constant pressure and calculated the heat of formation of $\mathrm{CF}_{4}(\mathrm{~g})$ to be $-220.4 \mathrm{kcal} \mathrm{mol}^{-1}$. Kirkbride and Davidson [6], and von Wartenberg [7,8] measured the heat of reaction of carbon tetrafluoride with potassium

*This research was sponsored by the Air Force Aero Propulsion Laboratory, Research and Development Division, Air Force Systems Command, Wright-Patterson Air Force Base, Ohio, under USAF Delivery Order No. 33(615)64-1003 and by the Air Force Office of Scientific Research under Order No. OAR ISSA 65-8.

${ }^{1}$ Figures in brackets indicate the literature references at the end of this paper. and from their measurements, respectively, calculated the heat of formation of $\mathrm{CF}_{4}(\mathrm{~g})$ to be -218 and $-231 \mathrm{kcal} \mathrm{mol}^{-1}$. Von Wartenberg and Schiefer [9] then made an adjustment to the work of Kirkbride and Davidson, and suggest an average value, -225 kcal mol ${ }^{-1}$. Vorob'ev and Skuratov [10] calculated for $\mathrm{CF}_{4}(\mathrm{~g}), \Delta H_{f 298}^{\circ}=-219.2 \mathrm{kcal} \mathrm{mol}^{-1}$ from a similar reaction except that sodium was used instead of potassium. Duus [11] calculated $\Delta H_{f 298}^{\circ}=-212.7$ $\mathrm{kcal} \mathrm{mol}^{-1}$ for carbon tetrafluoride from measurements on the explosive decomposition, explosive hydrogenation and oxygen combustion of $\mathrm{C}_{2} \mathrm{~F}_{4}(\mathrm{~g})$. Neugebauer and Margrave [12] studied the decomposition and the hydrogenation of $\mathrm{C}_{2} \mathrm{~F}_{4}(\mathrm{~g})$ and calculated for $\Delta H_{f 298}^{\circ}$ $\left[\mathrm{CF}_{4}(\mathrm{~g})\right],-217.1 \mathrm{kcal} \mathrm{mol}^{-1}$. Work by Baibuz [13] on the explosion of $\mathrm{CF}_{4}, \mathrm{H}_{2}, \mathrm{O}_{2}$, and $\mathrm{CO}$ mixtures led him to calculate for the heat of formation of $\mathrm{CF}_{4}(\mathrm{~g}),-220.1$ $\pm 1.4 \mathrm{kcal} \mathrm{mol}^{-1}$. Corrections for certain heat losses were later made for this study by Baibuz and Medvedev [14], and upon recalculation they found $\Delta H_{f 298}^{\circ}\left[\mathrm{CF}_{4}(\mathrm{~g})\right]$ $=-220.6 \mathrm{kcal} \mathrm{mol}^{-1}$.

Recent work by Cox, Gundry, and Head [15] on the heats of combustion of docosafluorobiscyclohexyl and docosafluorobiscyclohexyl-benzoic acid mixtures in oxygen led to $\mathrm{CO}_{2}$ and $\mathrm{CF}_{4}$ in the combustion products. They calculated the heat of formation of $\mathrm{CF}_{4}(\mathrm{~g})$ to be $-218.56 \mathrm{kcal} \mathrm{mol}^{-1}$ or $-225.63 \mathrm{kcal} \mathrm{mol}^{-1}$, depending upon whether they used the value for the 
heats of formation of $\mathrm{HF}(\mathrm{aq})$ as recommended in NBS Circular 500 [16], or as determined by Cox and Harrop [17], respectively. Past work in this laboratory [18] on the combustion of Teflon in fluorine led to a value of $-221.8 \mathrm{kcal} \mathrm{mol}^{-1}$ for the heat of formation of $\mathrm{CF}_{4}(\mathrm{~g})$. There are also many review articles and compilations in the literature which attempt to select a "best value" for the heat of formation of carbon tetrafluoride $[16,19,20,21]$.

The above work is discussed further in a later section of this paper. For the present, it is sufficient to note that all determinations so far reported, save that by von Wartenberg and Schütte [1], require values for the heat of formation of $\mathrm{HF}(\mathrm{g}), \mathrm{HF}(\mathrm{aq}), \mathrm{KF}(\mathrm{c})$ or $\mathrm{NaF}(\mathrm{c})$. In deriving values from the relationship to $\mathrm{KF}$ or $\mathrm{NaF}$, the tendency also has been to draw upon values of the heats of formation of these two salts derived from reactions involving $\mathrm{HF}$. The recently developed uncertainty in the heat of formation of HF has rendered all of these values questionable until the heat of formation of $\mathrm{HF}$ is more firmly established. In undertaking the study reported in this paper we have taken advantage of improved combustion techniques to attempt a redetermination of the heat of formation of $\mathrm{CF}_{4}(\mathrm{~g})$ by direct combination of the elements, and thus to avoid reliance upon auxiliary heats of formation.

\section{Materials}

\subsection{Graphite}

The sample used was spectroscopic grade graphite powder, having a particle size which passed 35 but was retained on 100 mesh screen; the total ash content stated by the manufacturer did not exceed $10 \mathrm{ppm}$. Analysis by the NBS Analysis and Purification Section showed that no significant metallic impurities were present in the sample. A neutron activation analysis showed oxygen and nitrogen in the sample to be $<86 \mathrm{ppm}$ and $<204 \mathrm{ppm}$, respectively. The NBS Crystallography Section made an $x$-ray diffraction pattern, and calculated $a=2.460 \AA$ and $c=6.721 \AA$ for the lattice parameters, in reasonable agreement with the literature values $a=2.464 \AA$ and $c=6.736 \AA$ [22].

\subsection{Polytetrafluoroethylene}

Two batches of polytetrafluoroethylene were used in the combustion experiments. These were designated by the manufacturer as TFE Fluorocarbon Resins "Teflon 5" and "Teflon 7". Both batches of powder were composed of irregularly shaped particles which adhered to one another. "Teflon 5" powder ranged in size from 50 to $800 \mu$ while those of "Teflon 7 " ranged from 10 to $500 \mu$. A thermosealable polytetrafluoroethylene film designated as FEP Fluorocarbon film, type A, was also used in preparing combustion samples. It had a thickness of 0.0025 $\mathrm{cm}$. Neither the powders nor the film were modified or treated in any special way prior to use. In the remainder of this paper, the polytetrafluoroethylene materials will be referred to simply as Teflon except when a more precise terminology is important to the meaning.

\subsection{Fluorine}

The fluorine used in the heat measurements was a specially prepared high-purity commercial material. By our assay it was 99.79 mole percent $F_{2}$. The analytical technique involved absorbing the fluorine in mercury and observing the pressure of the residual gases [23]. The volatile residue was examined in a mass spectrometer. ${ }^{2}$ Typical results for the composition of the residue normalized to 0.21 percent total residue are shown in table 1 .

TABLE 1. Analysis of fluorine

\begin{tabular}{|c|c|}
\hline Constituent & Mole percent \\
\hline $\mathrm{F}_{2}$ & 99.79 \\
\hline $\mathrm{O}_{2}$ & 0.1277 \\
\hline $\mathrm{N}_{2}$ & .0584 \\
\hline $\mathrm{CO}_{2}$ & .0106 \\
\hline $\mathrm{CF}_{4}$ & .0103 \\
\hline $\mathrm{Ar}$ & .0003 \\
\hline $\mathrm{SO}_{2} \mathrm{~F}_{2}$ & .0009 \\
\hline $\mathrm{SiF}_{4}$ & .0003 \\
\hline $\mathrm{C}_{2} \mathrm{~F}_{6}$ & .0007 \\
\hline $\mathrm{SF}_{6}$ & .0001 \\
\hline $\mathrm{C}_{4} \mathrm{~F}_{8}$ & .0005 \\
\hline $\mathrm{C}_{3} \mathrm{~F}_{8}$ & .0001 \\
\hline $\mathrm{C}_{2} \mathrm{~F}_{4}$ or cyclic $\mathrm{C}_{4} \mathrm{~F}_{8}$ & .0001 \\
\hline Total & 100.0000 \\
\hline
\end{tabular}

\section{Preparation of Graphite-Teflon Pellets}

The development of the technique for mixing a powdered sample with Teflon powder and pressing the mixture into pellet form has been described earlier [18]. This technique has been improved by using a Teflon bag to weigh and mix the constituent powders, ${ }^{3}$ giving not only better homogeneity but, more important, reducing sample losses during preparation by approximately an order of magnitude. In similar heat measurements on boron and metallic borides to be described in subsequent publications, an additional Teflon coating over the prepared pellet was required to prevent either spontaneous combustion or premature reaction prior to the desired ignition. The need for this Teflon coating was not absolutely certain in the case of graphite, as can be seen by comparing the combustion experiments (table 6, experiments 1,2 , 3,6 , and 7 ), in which a coated pellet was used, to those (table 6, experiments 4 and 5) in which the extra coating was absent. The procedure followed in preparing a pellet using the bag technique is described below as Method A, while the procedure for providing an additional Teflon coating is described under Method B.

Method A. A thermoplastic Teflon bag was prepared from a $6.5 \mathrm{~cm} \times 8.0 \mathrm{~cm}$ piece of FEP film by folding it over once and sealing two sides. Figure 1(a) illustrates the sealing of a piece of film. The ends to be sealed were folded over about three $\mathrm{mm}$ and the exposed folded edge was allowed to protrude from

\footnotetext{
${ }^{2}$ Analyses were performed by the NBS Analysis and Purification Section.

${ }^{3}$ The Teflon bag technique was developed by K. L. Churney in our laboratory.
} 

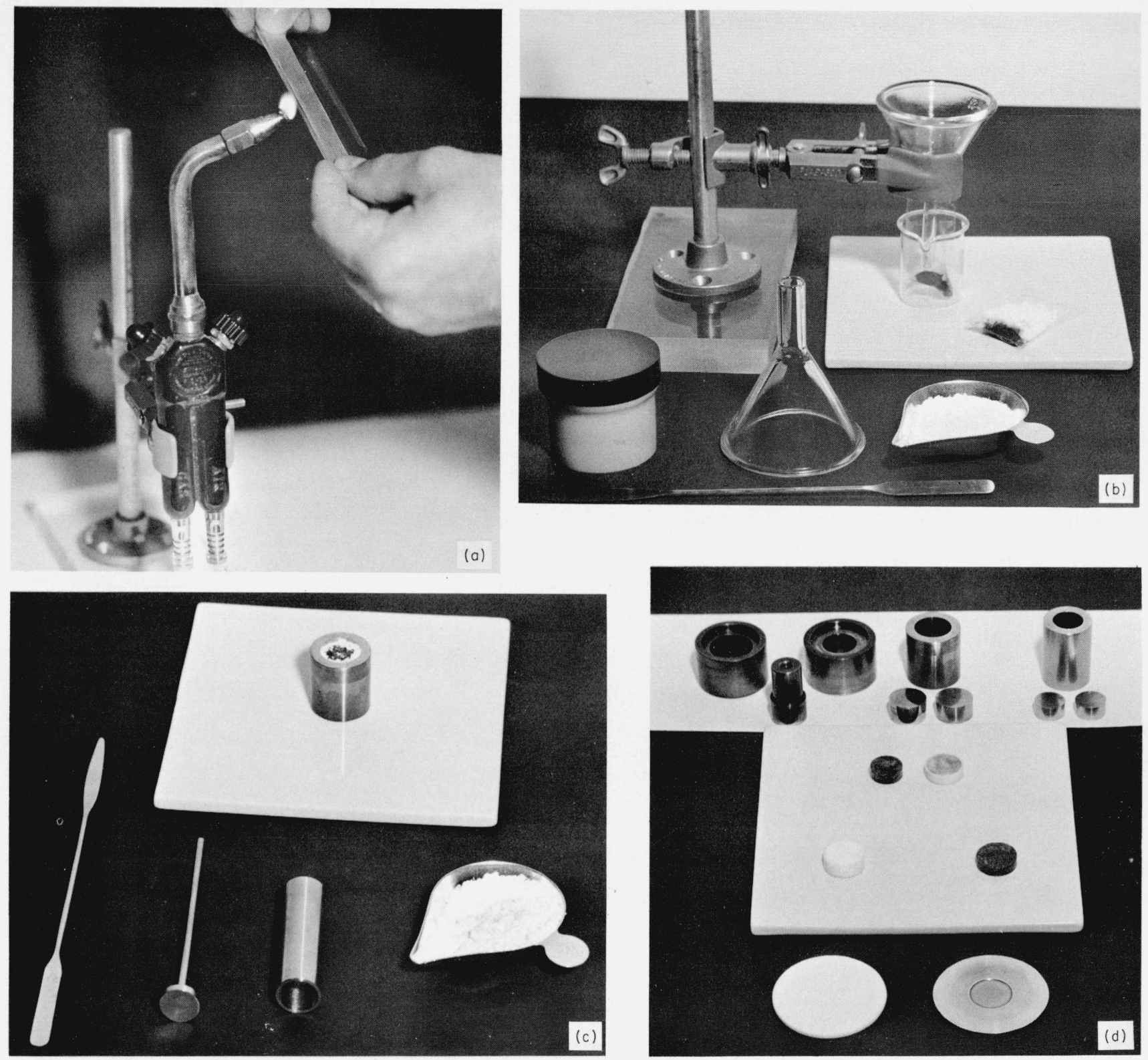

FIGURE 1. Procedures used in preparing the graphite-Teflon pellets for combustion.

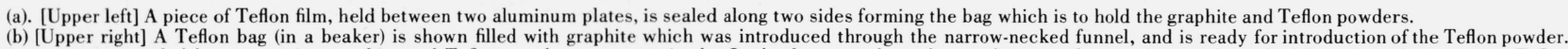

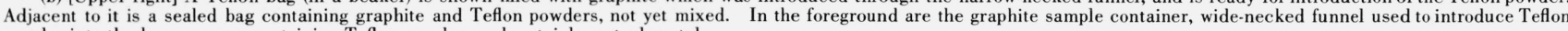
powder into the bag, a scoop containing Teflon powder, and a stainless steel spatula.

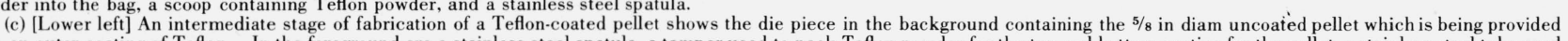

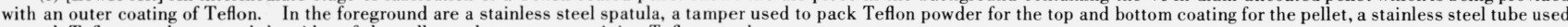
to pack Teflon powder around the sides of the pellet and a scoop containing Teflon powder.

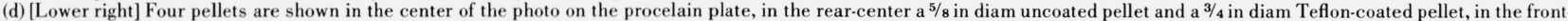

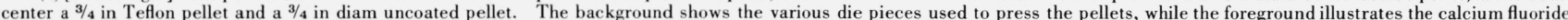
plate and nickel plate used to support the pellets during combustion.

between two aluminum plates $(10 \mathrm{~cm} \times 13 \mathrm{~cm} \times 0.16 \mathrm{~cm})$ about one $\mathrm{mm}$ as it was passed through a flame. The bag was placed in a $20 \mathrm{~cm}^{3}$ beaker, and the graphite powder and Teflon powder were weighed consecutively inside the bag. The remaining open end of the bag was sealed, and the graphite and Teflon were mixed. Care was taken not to exclude air from inside the bag before the final seal was made since it facilitated the mixing operation. By wearing a pair of polyethylene gloves, the operator could manipulate the sealed bag without contaminating it and adequately mix the two powders. A Teflon bag filled with graphite powder is shown in figure 1(b) along with a filled bag that has been sealed, but whose contents have not been mixed. After the contents had been mixed, the bag was placed in the pellet die, pierced with a needle to allow the air 
to escape, and the pellet was pressed. Losses observed in the sealing operation were assumed to be Teflon exclusively. In the pelleting of the bagged mixture, we assumed the losses to take place in proportion to the amounts of each constituent in the pellet.

Method B. The graphite powder was prepared in pellet form by mixing with Teflon in a Teflon bag as in Method A, except that the die pieces used to press the pellet were smaller ( 0.625 in diam) than those used in the previous pelleting operations $(0.75$ in diam). The smaller pellet was then placed inside the larger pellet die on a thin layer of packed Teflon powder. By tamping with a stainless steel tube of appropriate wall thickness, additional Teflon powder was packed into the space between the pellet and the wall of the die piece. Figure 1(c) shows that particular stage in the preparation of a coated pellet just prior to introducing the top layer of Teflon powder. After the latter layer was introduced, the contents of the die were pressed, giving a coating of Teflon around the smaller pelleted mixture. Figure $1(\mathrm{~d})$ shows the die pieces used in pressing the pellets, several types of prepared pellets, and the support plates upon which the pellets were burned.

In table 2, a brief summary is given of the typical quantities of Teflon and graphite which made up pellets prepared by Methods A and B.

Samples were weighed to the nearest $0.01 \mathrm{mg}$. The densities of the Teflon film and the two powders were determined as part of this investigation. The Teflon film had a density of $2.15 \mathrm{~g} \mathrm{~cm}^{-3}$ and the pelleted powders "Teflon 5" and "Teflon 7" had densities of 2.23 $\mathrm{g} \mathrm{cm}^{-3}$ and $2.16 \mathrm{~g} \mathrm{~cm}^{-3}$, respectively. The density of graphite was taken as $2.26 \mathrm{~g} \mathrm{~cm}^{-3}$ [24].

TABĹE 2. Typical quantities of graphite and Teflon used in combustion sample preparation

\begin{tabular}{|c|c|c|}
\hline 1. Method of preparation... & A & B \\
\hline 2. No. of experiments using the method.. & 2 & 5 \\
\hline 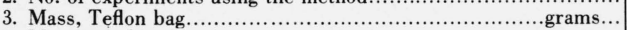 & 0.3 & 0.3 \\
\hline 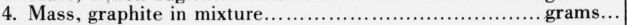 & 0.26 & 0.26 \\
\hline 5. Mass, Teflon in mixture ..........................................grams... & 2.24 & 1.30 \\
\hline 6. Mass, Teflon coating.......................................... grams... & & 0.8 \\
\hline 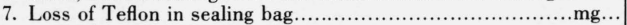 & 0.20 & 0.13 \\
\hline 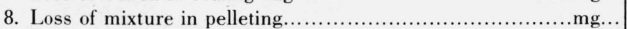 & 0.08 & 0.22 \\
\hline 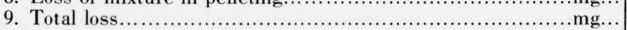 & 0.28 & 0.35 \\
\hline
\end{tabular}

\section{Calorimetric Apparatus}

An isothermal-jacket, stirred-water calorimeter was used for the heat measurements as described earlier [18]. The jacket was maintained isothermal within a range of $\pm 0.002{ }^{\circ} \mathrm{C}$ near $30^{\circ} \mathrm{C}$ by an electronic thermoregulator using a nickel resistance thermometer as a sensing element. Temperature differences were measured to $0.0001{ }^{\circ} \mathrm{C}$ with a G-2 Mueller Bridge in conjunction with a $25 \Omega$ platinum resistance thermometer. A heater was used in both calibration and combustion experiments in order to bring the calorimeter to the desired starting temperature.

The "A" nickel combustion bomb, fluorine manifold, and procedures for loading and emptying the combustion bomb with fluorine have been previously described [18]. A ballast tank was added to the manifold so that the emptying and purging of large amounts of fluorine $(0.3$ mole) could be done more safely at low pressures $(2-3 \mathrm{~atm})$. In the fluorine combustion experiments tungsten fuses of about $5 \mathrm{~cm}$ length, of either $0.005 \mathrm{~cm}$ or $0.0075 \mathrm{~cm}$ diam, were used, which contributed about $20 \mathrm{~J}$ or $40 \mathrm{~J}$, respectively, to the combustion energy if burned completely.

\section{Products of Combustion}

Our previous work [18] has established that Teflon burns in 15 to 20 atm of fluorine to form carbon tetrafluoride as the only major product. In the products of Teflon combustion in that work the content of higher fluorocarbons was estimated to be not more than 0.02 mole percent.

TABLE 3. Typical mass spectrometric analyses of combustion products (excluding fluorine)

\begin{tabular}{|c|c|c|c|c|c|}
\hline $\begin{array}{c}\text { Combus- } \\
\text { tion } \\
\text { products }\end{array}$ & $\begin{array}{l}\text { "Teflon } 5 " \\
\text { combustion } \\
\text { table } 4, \\
\text { exp. } 10\end{array}$ & $\begin{array}{l}\text { "Teflon 7" } \\
\text { combustion } \\
\text { table } 5 \text {, exp. } 7\end{array}$ & $\begin{array}{c}\text { Graphite- } \\
\text { "Teflon 7" } \\
\text { combustion } \\
\text { table 6, exp. } 2\end{array}$ & $\begin{array}{c}\text { Graphite- } \\
\text { "Teflon 7" } \\
\text { combustion } \\
\text { table } 6 \text {, exp. } 3\end{array}$ & $\begin{array}{l}\text { Graphite- } \\
\text { "Teflon 7" } \\
\text { combustion } \\
\text { table } 6 \text {, exp. } 6\end{array}$ \\
\hline $\begin{array}{l}\mathrm{N}_{2} \\
\mathrm{O}_{2} \\
\mathrm{CO}_{2} \\
\mathrm{CF}_{4} \\
\mathrm{SO}_{2} \mathrm{~F}_{2} \\
\mathrm{SiF}_{4} \\
\mathrm{C}_{2} \mathrm{~F}_{6} \\
\mathrm{SF}_{6}\end{array}$ & $\begin{array}{c}0.41 \\
1.23 \\
0.48 \\
97.8 \\
0.022 \\
\ldots \ldots \ldots \ldots \\
0.033 \\
.005\end{array}$ & $\begin{array}{c}0.34 \\
.32 \\
.087 \\
99.2 \\
0.007\end{array}$ & $\begin{array}{c}0.47 \\
.78 \\
.35 \\
98.4 \\
0.006 \\
.008 \\
.044\end{array}$ & $\begin{array}{r}0.33 \\
.51 \\
.21 \\
98.9 \\
0.008 \\
.005 \\
.024 \\
.006\end{array}$ & $\begin{array}{c}0.45 \\
.66 \\
.24 \\
98.6 \\
0.011 \\
.018 \\
.018 \\
.006\end{array}$ \\
\hline
\end{tabular}

(Composition given in mole percent.)

Table 3 gives typical mass spectrometer analyses (see footnote 2) of the reaction products of Teflon and graphite-Teflon combustion experiments. After a combustion experiment, the gas mixture in the bomb was expanded into the ballast tank attached to the fluorine manifold to reduce the operating pressure to about 3 atm abs. A sample of gas was then taken from the manifold into an evacuated glass bulb $\left(250 \mathrm{~cm}^{3}\right)$ containing some mercury. The fluorine was reacted with the mercury and the residual gases were examined in a mass spectrometer. The compositions are shown in table 3 and represent about 25 mole percent of the final gas in the bomb as a result of removing the fluorine prior to analysis. The observed quantities of $\mathrm{O}_{2}$, $\mathrm{N}_{2}, \mathrm{CO}_{2}, \mathrm{C}_{2} \mathrm{~F}_{6}, \mathrm{SiF}_{4}, \mathrm{SO}_{2} \mathrm{~F}_{2}$, and $\mathrm{SF}_{6}$ are larger than are expected in the final bomb product gases on the basis of the original composition of the fluorine by as much as an order of magnitude. After considering several side reactions which might have served as sources of the impurities, when we applied corrections to the combustion data for the reactions, we obtained an extremely high spread of the combustion values. We felt that the good precision obtained from the uncorrected values was more indicative of the reaction taking place during the heat measurements and suggest that the anomalously high amounts of bomb gases other than $\mathrm{CF}_{4}$ were introduced during sampling or analysis procedures. The amounts of $\mathrm{C}_{2} \mathrm{~F}_{6}(\mathrm{~g})$ observed in the graphite-Teflon experiments were com- 
parable to those observed in the combustion of Teflon alone. Although higher fluorocarbons could be present at levels below the limit of detection of the mass spectrometer (approximately 0.01 mole percent), we assumed them to be absent.

\section{Calibration Experiments}

Twenty calibration experiments were made with benzoic acid over a three year period. Benzoic acid standard sample $39 \mathrm{i}$ was burned in a platinum crucible in the presence of $30 \mathrm{~atm}$ of oxygen and $1 \mathrm{ml}$ of distilled water in the nickel combustion bomb. The experiments were performed in three series, an initial series of six experiments, a second series of ten and a final series of four experiments. All twenty experiments were found to be statistically equivalent and when averaged gave an energy equivalent of $14,803.27$ $\pm 0.99 \mathrm{~J} \mathrm{deg}^{-1}$. The uncertainty cited is the standard deviation of the mean. The energy equivalent given is that for the standard calorimeter, which consisted of the nickel combustion bomb with $30 \mathrm{~atm}$ of oxygen, a platinum crucible and fuse support wires, platinum fuse ( $2 \mathrm{~cm}$ in length, $0.01 \mathrm{~cm}$ diam), a type 304 stainlesssteel liner, monel pellet holder, no sample, a heater, ignition leads fastened to the bomb, the calorimeter vessel with lid and stirrer, and water. The mass of the calorimeter vessel with water and stirrer was $3750.0 \mathrm{~g}$.

Using the appropriate heat capacity data, the energy equivalent of the standard calorimeter to be used in the fluorine combustion experiments was calculated to be $14,805.17 \mathrm{~J} \mathrm{deg}^{-1}$. This involved subtracting the heat capacities of $30 \mathrm{~atm}$ of oxygen, one $\mathrm{ml}$ of distilled water and the platinum ware and adding the heat capacities for 21 atm of fluorine and two aluminum electrodes.

\section{Fluorine Combustion Experiments}

Ten calorimetric experiments were performed in which "Teflon 5" was burned in fluorine. Like the benzoic acid calibration experiments, they were done over a three year period in series of four, three and three, and show excellent agreement over this length of time. Seven calorimetric experiments were performed in which "Teflon 7" was burned in fluorine, followed by seven calorimetric experiments of graphite-"Teflon 7" pellets in fluorine.

A fluorine pressure of 21 to 22 atm was used in all experiments except two "Teflon 5" combustions for which the fluorine pressure was 16 to 17 atm. In each experiment the sample pellet was placed in the recess of the monel holder or nickel plate, the bomb attached to the fluorine manifold and filled with fluorine to the desired pressure. All bomb parts (bomb base, bomb head assembly and electrodes, liner, and sample plate) were weighed before the first experiment and after each experiment. The bomb parts were washed with water and dried before the weighings were made. Although changes in weight of the bomb parts were almost imperceptible from experiment to experiment, a definite decrement in weight was observed over an extended period of time which we attributed to corrosion by fluorine.

Tables 4, 5, and 6 give the data for individual experiments on "Teflon 5", "Teflon 7", and graphite-"Teflon 7" mixtures, respectively.

The numbered entries in the tables are as follows:

(la) Mass of the graphite sample mixed with Teflon in the pellet, corrected for weight loss in preparation and for recovery of unburned sample.

(1b) Mass of Teflon mixed with graphite sample in the pellet, corrected for weight loss.

(2) Pressure of fluorine introduced into the bomb prior to combustion, corrected to $30^{\circ} \mathrm{C}$.

(3) Energy equivalent of the calorimeter for a given experiment. This includes adjustments for excess fluorine, the nickel support, and the calcium fluoride support when used.

(4) Temperature change of the calorimeter thermometer corrected for heat of stirring and heat transfer.

(5) Total energy change in the bomb process.

(6) Energy liberated by the tungsten fuse assuming the fuse burns according to the reaction: $\mathrm{W}(\mathrm{c})+3 \mathrm{~F}_{2}(\mathrm{~g})$ $=\mathrm{WF}_{6}(\mathrm{~g})$. From the heat of formation of $\mathrm{WF}_{6}$ [25], we calculate $9.44 \mathrm{~J} \mathrm{mg}^{-1}$ for the energy of combustion of the fuse.

(7) Net energy correction for the hypothetical compression and decompression of bomb gases.

$$
\left.\left.\Delta E \text { gas }=\Delta E^{i}(\text { gas })\right]_{0}^{P^{i(\text { gas })}}+\Delta E^{f}(\text { gas })\right]_{P_{(\text {gas })}^{0}}
$$

TABLE 4. "Teflon 5" combustion experiments

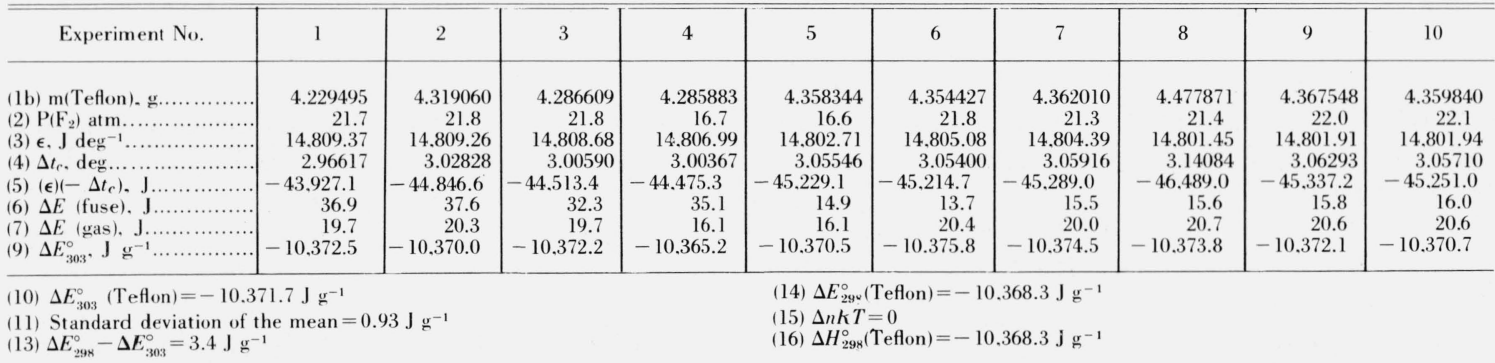


TABLE 5. “Teflon 7" combustion experiments

\begin{tabular}{|c|c|c|c|c|c|c|c|}
\hline Experiment No. & 1 & 2 & 3 & 4 & 5 & 6 & 7 \\
\hline 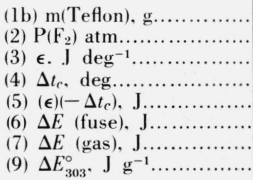 & $\begin{array}{r}4.446597 \\
22.1 \\
14.801 .56 \\
3.11882 \\
-46.163 .4 \\
18.9 \\
21.1 \\
-10.372 .7\end{array}$ & \begin{tabular}{|r|}
4.367727 \\
22.1 \\
$14,801.93$ \\
3.06456 \\
-45.361 .4 \\
19.4 \\
21.0 \\
-10.376 .3
\end{tabular} & \begin{tabular}{|r|}
4.546440 \\
22.2 \\
$14,801.94$ \\
3.18913 \\
-47.205 .3 \\
18.6 \\
21.7 \\
-10.374 .1
\end{tabular} & $\begin{array}{r}4.443729 \\
22.3 \\
14.802 .21 \\
3.11615 \\
-46,125.9 \\
17.5 \\
21.3 \\
-10.371 .3\end{array}$ & $\begin{array}{r}4.472263 \\
22.2 \\
14.762 .58 \\
3.14506 \\
-46.429 .2 \\
19.9 \\
21.4 \\
-10.372 .4\end{array}$ & $\begin{array}{r}4.367187 \\
21.9 \\
14.718 .29 \\
3.08065 \\
-45.341 .9 \\
19.5 \\
20.5 \\
-10.373 .2\end{array}$ & $\begin{array}{r}4.395447 \\
22.0 \\
14.760 .24 \\
3.09083 \\
-45.621 .4 \\
20.4 \\
20.8 \\
-10.369 .9\end{array}$ \\
\hline \multicolumn{8}{|c|}{$\begin{array}{l}\text { (10) } \Delta E_{303}^{\circ} \text { (Teflon) }=10.372 .8 \mathrm{~J} \mathrm{~g}^{-1} \\
\text { (11) Standard deviation of the mean }=0.77 \mathrm{~J} \mathrm{~g}^{-1} \\
\text { (13) } \Delta E_{298}^{\circ}-\Delta E_{303}^{\circ}=3.4 \mathrm{~J} \mathrm{~g}^{-1} \\
\text { (14) } \Delta E_{298}^{\circ} \text { (Teflon) }=-10.369 .4 \mathrm{~J} \mathrm{~g}^{-1} \\
\text { (15) } \Delta n R T=0 \\
\text { (16) } \Delta H_{298}^{\circ} \text { (Teflon) }=-10.369 .4 \mathrm{~J} \mathrm{~g}^{-1}\end{array}$} \\
\hline
\end{tabular}

TABLE 6. Graphite- "Teflon 7" combustion experiments

\begin{tabular}{|c|c|c|c|c|c|c|c|}
\hline Experiment No. & 1 & 2 & 3 & 4 & $5^{a}$ & $6^{a}$ & $7^{a}$ \\
\hline (1a) $\mathrm{m}$ (samp & 0.243088 & 0.255922 & 0.264152 & 0.251913 & 0.256820 & 0.256785 & 0.252724 \\
\hline (lb) $\mathrm{m}(\mathrm{Tef}$ & 2.419090 & 2.475588 & 2.468792 & 2.592377 & 2.478479 & 2.593593 & 2.468206 \\
\hline (2) $\mathrm{P}\left(\mathrm{F}_{2}\right)$ atm... & 21.1 & 21.6 & 22.1 & 21.8 & 21.6 & 21.4 & 21.5 \\
\hline (3) $\epsilon, J \mathrm{Jeg}^{-1}$. & $14,758.06$ & 14.757 .62 & $14,749.66$ & 14.749 .65 & 14.760 .77 & 14.785 .54 & 14.760 .23 \\
\hline (4) $\Delta t_{c}$, deg.. & 2.97695 & 3.08524 & 3.12481 & 3.14697 & 3.09070 & 3.16518 & 3.06065 \\
\hline (5) $(\boldsymbol{\epsilon})\left(-\Delta t_{c}\right), J$. & -43.934 .0 & -45.530 .8 & -46.089 .9 & -46.416 .7 & -45.621 .1 & -46.798 .9 & -45.175 .9 \\
\hline (6) $\Delta E$ (fuse), J. & 17.2 & 18.9 & 20.4 & 19.5 & 16.0 & 16.0 & 20.4 \\
\hline (7) $\Delta E$ (gas), J. & 8.4 & 8.8 & 9.4 & 9.4 & 8.8 & 9.3 & 8.7 \\
\hline (8) $\Delta E^{\circ}$ (Teflon), J & $25,092.7$ & $25,678.8$ & $25,608.3$ & $26,890,2$ & 25.708 .8 & 26.902 .8 & $25,602.2$ \\
\hline (9) $\Delta E_{303}^{\circ}$ (sample) $\mathrm{J} \mathrm{g}^{-1}$ & -77.402 .8 & $-77,462.3$ & -77.424 .4 & -77.398 .1 & -77.437 .5 & $-77,383.0$ & -77.335 .7 \\
\hline
\end{tabular}

(10) $\Delta E_{303}^{\circ}$ (graphite sample) $=-77,406.3 \mathrm{~J} \mathrm{~g}^{-}$

(11) Standard deviation of the mean $=15.5 \mathrm{~J} \mathrm{~g}^{-1}=0.04 \mathrm{kcal} \mathrm{mol}^{-1}$

(12) Contribution from impurities $0.0 \mathrm{~J} \mathrm{~g}^{-1}$ for 0.029 percent impurities

(13) $\Delta E_{298}^{\circ}-\Delta E_{303}^{\circ}=0.8 \mathrm{~J} \mathrm{~g}^{-1}$

(14) $\Delta E_{\text {.98 }}^{\circ}$ (graphite) $=-77.428 .0 \mathrm{~J} \mathrm{~g}^{-1}$

(15) $\Delta n R T=-206.4 \mathrm{~J} \mathrm{\alpha}^{-1}$

(16) $\Delta H_{298}^{\circ}$ (graphite) $=-77,634.4 \mathrm{~J} \mathrm{~g}^{-1}=-222.87 \mathrm{kcal} \mathrm{mol}^{-1}$

a The nickel plate was supported on a $\mathrm{CaF}_{2}$ plate in these experiments.

(8) Standard energy of combustion per gram of Teflon at $30{ }^{\circ} \mathrm{C}$ multiplied by the corrected mass of Teflon in the pellet, given in (1b).

(9) Standard energy of combustion per gram of the sample.

(10) Average standard energy of combustion per gram of the sample.

(11) Standard deviation of the mean of the average cited in (10).

(12) Energy contribution by impurities.

(13) Energy correction converting the reference temperature to $298{ }^{\circ} \mathrm{K}$.

(14) Standard energy of combustion of the pure substance, corrected to zero impurity.

(15) $\Delta n R T$ term.

(16) Standard enthalpy of combustion at $298^{\circ} \mathrm{K}$.

The heat capacities at constant pressure, $C_{p}$, used in the calculation of entries (3) and (13) are as follows in cal $\mathrm{deg}^{-1}$ gram $^{-1}$ : Teflon, 0.28 [4]; graphite, 0.170 [26]; and calcium fluoride, 0.205 [16]. The heat capacities at constant volume, $C_{v}$, used in the calculation of entries (3) and (13) for fluorine and carbon tetrafluoride were 5.52 [27] and 12.62 [28] $\mathrm{cal} \mathrm{deg}^{-1}$ $\mathrm{mol}^{-1}$, respectively.

Washburn corrections in entry (7) were calculated following the procedure outlined by Hubbard [29] for experiments in which fluorine is used as an oxidant. The coefficients $[\partial E / \partial P]_{T}=-T[d B / d T]$ were found in tables based on a Lennard-Jones 6-12 potential function as compiled by Hirschfelder, Curtiss, and Bird [30] using the appropriate force constants. The force constants for fluorine and carbon tetrafluoride were those determined by White, Hu, and Johnston [31], and by Douslin [32], respectively. Force constants appropriate to the mixtures of $\mathrm{F}_{2}$ and $\mathrm{CF}_{4}$ in the reaction products were calculated from those of the pure components.

We assumed that the oxygen and nitrogen impurities found in the graphite were present as the elements and underwent no reaction. As oxygen and nitrogen were the only significant impurities, the energy contributed by the impurity reactions was zero. However, a small mass correction was made in entry (12) for the masses of oxygen and nitrogen present.

Atomic weights were taken from the 1961 table of atomic weights based on carbon- 12 and adopted by the International Union of Pure and Applied Chemistry [33]. The unit of energy is the joule, and one calorie was taken as $4.1840 \mathrm{~J}$.

The raw data obtained in the benzoic acid calibration experiments were programmed for the IBM 7094 computer according to procedures outlined by Shomate [34] for the computer calculation of combustion bomb calorimetric data, slightly modified to allow for curvature of the initial and final drift periods. The fluorine combustion experiments were similarly programmed; 
however, the only valid data calculated by the computer were the corrected temperature rises, $\Delta t_{c}$, because the program used had not been modified to accommodate the use of fluorine as the oxidant.

\section{Discussion and Results}

\subsection{Analysis of Combustion Residues}

A residue assumed to be unburned Teflon and/or carbon was observed in heat measurements involving Teflon alone; it was found to be less than 0.01 percent of the initial mass of the Teflon. No correction was applied to tables 4,5 , or 6 for this residue, and we assumed that the formation of the residue took place in all experiments approximately in proportion to the amount of Teflon initially present. The heat of combustion per gram of Teflon would, hence, be constant and the error due to residue formation would be eliminated when the energy due to the combustion of Teflon was subtracted from the total energy released in the combustion.

Significantly larger total residues were observed after the graphite combustion experiments, however, and an analysis of the residues was therefore essential to an accurate calculation of the amount of reaction. Because of the destructive nature of the analysis, both carbon and fluorine could not be determined in the same residue. The small amounts of residues also made blank determinations important. The following series of analyses (see foot note 2) were carried out in order to arrive at a reasonable understanding of the composition of the residue.

Ten Teflon-combustion experiments were performed in which the residue remaining after the combustion of a pellet was accurately weighed, collected with alumina powder, and analyzed for carbon. The collection of the residue was made by spreading about a gram of alumina powder over the residue on the support plate and working the alumina into the residue with a spatula. The carbon was determined gravimetrically as $\mathrm{CO}_{2}$ after combustion of the mixture of alumina powder and the residue in a carbonhydrogen analyzer.

Table 7 shows the results of the carbon analyses. Five samples of alumina powder were subjected to blank carbon analysis and an average blank of 0.04 $\mathrm{mg}$ was found. The average mass of Teflon-combustion residue was about $1.20 \mathrm{mg}$ of which the average carbon content was found to be $0.10 \mathrm{mg}$. Two blank experiments were performed in which Teflon powder was mixed with alumina powder and analyzed for carbon. These two blanks showed good agreement between the carbon content of the Teflon sample and carbon found by the $\mathrm{CO}_{2}$ determination. Three further blank experiments were performed in which a weighed amount of graphite powder mixed with alumina powder was subjected to carbon analysis. The carbon analyses were systematically low by about $0.8 \mathrm{mg}$ with respect to the original amount of graphite introduced. This showed the analytical technique gave good results in the analysis of carbon from the Teflon blank, but poor results for graphite blanks.
TABLE 7. Masses and carbon analyses of the residues of Teflon combustions

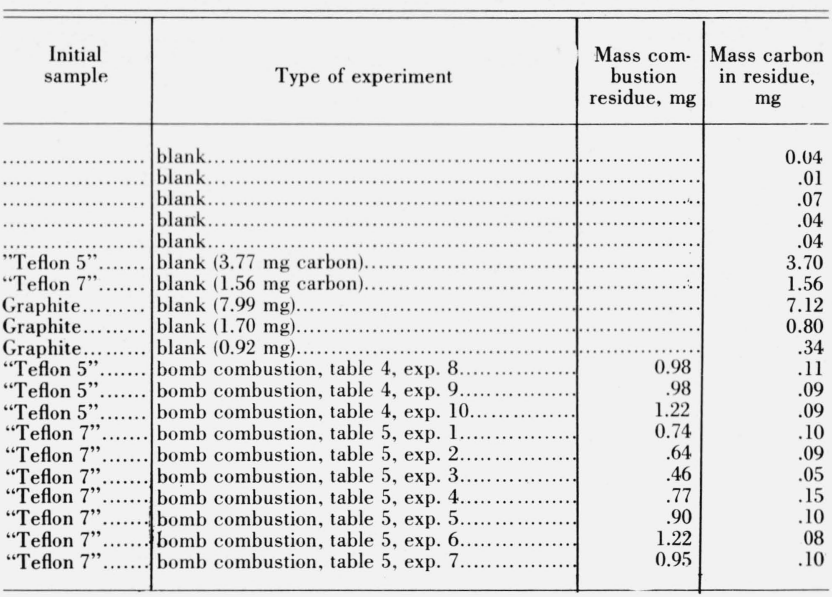

A noncalorimetric combustion of a Tetion pellet in 21 atm of fluorine was made which gave a residue weighing $0.65 \mathrm{mg}$. The residue was analyzed for fluorine content and showed $0.16 \mathrm{mg}$ of fluorine. Another Teflon residue weighing $0.51 \mathrm{mg}$ prepared similarly and analyzed for nickel showed $0.03 \mathrm{mg} \mathrm{Ni}$ present. A blank experiment to determine the fluorine content of Teflon powder gave only 90 percent of the expected value.

Besides fluorine and nickel, tungsten was present as a constituent of the residue. Tiny balls, ranging in diameter from $0.010 \mathrm{~cm}$ to $0.035 \mathrm{~cm}$ sprayed on top of the nickel plate as a result of fuse ignition were identified as tungsten by means of electron probe microanalysis (see footnote 2). If we assume that 10 balls of melted tungsten are formed per experiment, having diameters of $0.020 \mathrm{~cm}$, a mass increment of $0.8 \mathrm{mg}$ should be observed. The latter increment together with the fluorine analysis could account completely for the mass difference between the Teflon combustion residues and their carbon analyses.

Two experiments were performed (table 4, experiment 9 , table 5 , experiment 7 ) in which a $0.3 \mathrm{~g}$ Teflon bag was filled with Teflon powder, pressed and burned in fluorine in order to determine whether the presence of the Teflon bag affects the heat of combustion of Teflon. Another similar experiment was performed (table 4, experiment 10) in which a Teflon bag filled with Teflon powder was pressed and coated with an outer layer of Teflon. Combustion of neither this Teflon pellet nor the two uncoated Teflon pellets showed any departure from the expected value for the heat of combustion in fluorine. Examination of combustion residues showed about the same mass of carbon present here as for residues with no bag.

The masses of the residues obtained in the calorimetric experiments with graphite-Teflon pellets varied, depending upon the type of support used and particle size of the graphite. These experimental variations are shown in table 8 along with the masses and carbon analyses of the residues.

The first two experiments were made with a 0.125 in thick ( $45 \mathrm{~g})$ nickel plate under the sample, and left 
TABLE 8. Completeness of combustion in graphite-Teflon experiments

\begin{tabular}{|c|c|c|c|c|}
\hline $\begin{array}{c}\text { Exper. } \\
\text { No. }\end{array}$ & $\begin{array}{c}\text { Particle size } \\
\text { of graphite, } \\
\text { range in } \\
\text { microns }\end{array}$ & Type of sample support used & $\begin{array}{l}\text { Mass com- } \\
\text { bustion } \\
\text { residue }\end{array}$ & $\begin{array}{l}\text { Mass car- } \\
\text { bon in } \\
\text { residue }\end{array}$ \\
\hline & & & $m g$ & $m g$ \\
\hline $\begin{array}{l}1 \\
2\end{array}$ & $\begin{array}{l}150-420 \\
150-420\end{array}$ & 45 g nickel plate...... & $\begin{array}{l}10.31 \\
13.22\end{array}$ & 5.17 \\
\hline 3 & $150-420$ & 25 g nickel plate... & 7.78 & 4.17 \\
\hline 4 & $150-420$ & 25 g nickel plate.. & 10.18 & 5.88 \\
\hline 5 & $150-420$ & $25 \mathrm{~g}$ nickel plate and $13 \mathrm{~g} \mathrm{CaF}_{2}$ plate. & 3.02 & 1.93 \\
\hline 6 & $40-150$ & $26 \mathrm{~g}$ nickel plate and $13 \mathrm{~g} \mathrm{CaF}_{2}$ plate.. & 1.74 & 0.83 \\
\hline 7 & $40-150$ & $25 \mathrm{~g}$ nickel plate and $13 \mathrm{~g} \mathrm{CaF}_{2}$ plate................. & 0.80 & .28 \\
\hline
\end{tabular}

residues of 10 to $13 \mathrm{mg}$. Reducing the thickness of the nickel plate to 0.0625 in $(25 \mathrm{~g})$ caused no significant improvement in the degree of completeness of reaction (experiments 3 and 4). However, improvement came as a result of placing under the nickel plate, a 0.125 in thick calcium fluoride plate which increased the completeness of combustion from about 97 percent to better than 99 percent (experiment 5). Further improvement in the degree of completeness came as a result of grinding the sample to a smaller particle size $(40-150 \mu)$, and brought reactions to 99.7 to 99.9 percent completion (experiments 6 and 7). The percent completion was calculated using the mass of carbon found in the residue as compared to the initial mass of graphite in the sample. However, the large difference in mass between the weighed residue and the carbon determined by analyses cannot be ignored. In order to resolve this disparity, two non-calorimetric combustion experiments were performed in which graphiteTeflon pellets were burned in 21 atm of fluorine and residues analyzed for fluorine content. The residues weighed $13.77 \mathrm{mg}$ and $4.20 \mathrm{mg}$ and were found to contain $4.8 \mathrm{mg}$ and $1.1 \mathrm{mg}$ of fluorine, respectively.

A reasonably good accounting for the total composition of the combustion residues (table 8, column 4) from burning graphite-Teflon pellets in fluorine can now be made. Using the above data on the fluorine analysis of graphite-Teflon pellets and assuming a linear variation of the fluorine content with total mass, a value for the approximate fluorine content of a particular residue could be chosen. From this the carbon found by analysis could be divided into unburned graphite and carbon present as unburned Teflon. A correction was made for systematically low results in the analysis of graphite on the basis of data obtained from graphite blanks in table 7. Finally, a correction for the presence of melted tungsten fuse on the sample plate was applied. Each correction was weighted in proportion to the magnitude of the combustion residue found for a particular experiment. The amount of unburned graphite with a correction for the graphite blank was calculated for each experiment from these data and found to be almost identical with the uncorrected values found for the total of carbon content of the combustion residues (table 8, last column), the average difference being $0.23 \mathrm{mg}$. Applying corrections for unburned Teflon and unburned tungsten on a weighted basis tended to increase the spread of the data by a factor of three. This suggested that the distribution of unburned Teflon is not a linear function of the total mass of the combustion residue. Whether the same is true for the tungsten is not easily discernible since the applied correction is small.

Since we have been able to account for the composition of the combustion residue only in a semiquantitative manner, the uncorrected mass of carbon found in the residue was used as a measure of the unburned graphite. We felt this to be the best representation for our data because it produced a minimal spread, but have considered the uncertainties in the composition of the combustion residues in our discussion of errors. Hence, the mass of carbon given in the last column of table 8 was subtracted from the original mass of graphite in the pelleted mixture, and the adjusted mass appears in table 6 as entry (la).

\subsection{Mass Increments of Pellets Exposed to Fluorine}

Teflon pellets exposed to fluorine at pressures of 16 to $21 \mathrm{~atm}$ of fluorine, gained measurably in weight $(0.61 \mathrm{mg}$ in $21 \mathrm{hr}$, in one instance, and $2.65 \mathrm{mg}$ in 264 $\mathrm{hr}$ in another), and after subsequent exposure to air or vacuum, about 30 percent of the weight gain persisted. Vacuum treatment of two Teflon pellets caused small weight losses, which depended upon the time of exposure. In one such pellet, subsequent exposure to fluorine at 21 atm pressure resulted in only a small weight gain, which was lost upon further exposure to vacuum. This experiment was not repeated so the reproducibility of the results is not known. The persistence of the weight gain in pellets not treated by vacuum suggests that in the presence of moist air, fluorine absorbed in the pellet may be converted to $\mathrm{HF}$, which remains in the pellet along with the adsorbed moisture. A conversion of Teflon to $\mathrm{CF}_{4}$ does not occur as a weight loss would then be observed.

In $2.3 \mathrm{hr}$, exposure to fluorine at $21 \mathrm{~atm}$ pressure of an uncoated graphite-Teflon pellet gave a mass increment of about $2 \mathrm{mg}$ per hour. Upon subsequent exposure to air and vacuum it showed a weight loss of about 40 percent of the increment. A weight gain of $2 \mathrm{mg}$ per hour, if due to reaction of fluorine with graphite, would not lead to a perceptibly increased initial calorimeter drift rate. We feel that only a small possibility of error can be attributed to premature reaction. Details of the weight changes observed are given in table 9.

\subsection{Summary of Errors}

We have attempted to estimate the overall experimental error for the heats of combustion of Teflon and graphite in fluorine and have summarized the results in table 10. As a guide toward estimating the error due to the loss of sample during the pelleting operation, we have used the data in table 2 , line 8 . If the loss of mixture was not in proportion to the masses of Teflon and graphite present in the pellet, a maximum error of $13 \mathrm{~J}$ or about 0.07 percent could occur. The total loss of pellet was not used (table 2, line 9) since part of the loss was due to sealing the Teflon bag.

In estimating the error of assuming that the residue from a Teflon combustion was proportional to the 
TABLE 9. Mass increments of pellets after exposure to fluorine

\begin{tabular}{|c|c|c|c|c|c|}
\hline Test No. & 1 & 2 & 3 & 4 & 5 \\
\hline Type of pellet & "Teflon 7" & "Teflon 5" & "Teflon 5" & "Teflon 5" & $\begin{array}{l}\text { graphite-"Teflon 7" } \\
\text { (no coating) }\end{array}$ \\
\hline $\begin{array}{l}\text { Initial mass of pellet } \\
m_{0} \text {, grams }\end{array}$ & 4.24234 & 4.47363 & 4.23627 & 4.36031 & $\begin{array}{l}2.84575 \\
\quad(255 \mathrm{mg} \text { graphite) }\end{array}$ \\
\hline $\begin{array}{l}\text { Conditions (1) and mass } \\
\text { change, } m_{1}-m_{0}, \mathrm{mg}\end{array}$ & $\begin{array}{l}\text { in bomb } \\
21 \mathrm{~atm} \mathrm{~F}_{2} \\
21 \mathrm{hr} \\
+0.61\end{array}$ & $\begin{array}{l}\text { in bomb } \\
16 \text { atm } \mathrm{F}_{2} \\
11 \text { days } \\
+2.65\end{array}$ & $\begin{array}{l}\text { under } \\
\text { vacuum } \\
1.5 \mathrm{hr} \\
-0.06\end{array}$ & $\begin{array}{l}\text { under } \\
\text { vacuum } \\
7 \text { days } \\
-0.44\end{array}$ & $\begin{array}{l}\text { in bomb } \\
21 \mathrm{~atm} \mathrm{~F} \mathrm{~F}_{2} \\
2.3 \mathrm{hr} \\
+5.48\end{array}$ \\
\hline $\begin{array}{l}\text { Conditions (2) and mass } \\
\text { change, } m_{2}-m_{0}, \mathrm{mg}\end{array}$ & $\begin{array}{l}\text { exposed to air } \\
1.5 \text { days } \\
+0.42\end{array}$ & $\begin{array}{l}\text { under vacuum } \\
\quad 1 \text { day } \\
+1.92\end{array}$ & $\begin{array}{l}\text { in bomb } 21 \text { atm } \\
\mathrm{F}_{2} 6 \mathrm{hr} \\
+0.003\end{array}$ & - & $\begin{array}{l}\text { exposed to air } \\
21 \text { days } \\
+4.07\end{array}$ \\
\hline $\begin{array}{l}\text { Conditions }(3) \text { and mass } \\
\text { change, } m_{3}-m_{0}, \mathrm{mg}\end{array}$ & $\begin{array}{l}\text { exposed to air } \\
15 \text { days } \\
\text { and under } \\
\text { vacuum } 7 \mathrm{hr} \\
0.19\end{array}$ & $\begin{array}{l}\text { exposed to air } \\
6 \text { days } \\
+1.05\end{array}$ & $\begin{array}{l}\text { under vacuum } \\
30 \mathrm{~min} \\
-0.05\end{array}$ & - & $\begin{array}{l}\text { exposed to air } \\
21 \text { days } \\
+3.50\end{array}$ \\
\hline $\begin{array}{l}\text { Conditions (4) and mass } \\
\text { change, } m_{4}-m_{0}, \mathrm{mg}\end{array}$ & $\begin{array}{l}\text { exposed to air } \\
12 \text { days } \\
+0.24\end{array}$ & $\begin{array}{l}\text { exposed to air } \\
22 \text { days } \\
+0.80\end{array}$ & - & - & $\begin{array}{l}\text { exposed to air } 5 \text { days } \\
\text { under vacuum } 18 \mathrm{hr} \\
+3.34\end{array}$ \\
\hline
\end{tabular}

TABLE 10. Summary of errors

\begin{tabular}{|c|c|c|c|}
\hline \multirow{2}{*}{ Description of error } & \multicolumn{3}{|c|}{$\begin{array}{l}\text { Error in percent of } \Delta H_{298}^{\circ} \\
\text { for substance }\end{array}$} \\
\hline & "Teflon 5" & "Teflon 7" & graphite \\
\hline 1. Error due to loss of sample during preparation.. & & & 0.07 \\
\hline 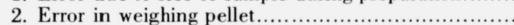 & 0.01 & 0.01 & 0.01 \\
\hline 3. Error from reaction prior to ignition.. & 0.01 & 0.01 & 0.01 \\
\hline 4. Combustion residue error................. & 0.005 & 0.005 & 0.10 \\
\hline 5. Error in giving no assignment to unburned Teflon.. & & & 0.10 \\
\hline 6. Error in fuse energy ................... & 0.01 & 0.01 & 0.01 \\
\hline 7. Error from bomb corrosion........ & 0.01 & 0.01 & 0.01 \\
\hline 8. Error in determining sample impurities... & & & 0.03 \\
\hline 9. Error in calibration experiments....... & 0.01 & 0.01 & 0.01 \\
\hline 10. Error in the energy of combustion of Teflon... & 0.02 & 0.02 & 0.02 \\
\hline $\begin{array}{l}\text { 11. Error in the energy of combustion of graphite- } \\
\text { Teflon pellets }\end{array}$ & & & 0.05 \\
\hline 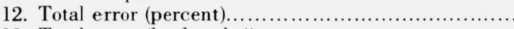 & 0.03 & 0.03 & 0.17 \\
\hline 13. Total error $\left(\mathrm{kcal} \mathrm{mol}^{-1}\right) \ldots \ldots$. & 0.07 & 0.07 & 0.38 \\
\hline
\end{tabular}

original mass of Teflon, the data in table 7 were used. Analysis of the Teflon combustion residues showed an average spread of $0.02 \mathrm{mg}$ giving an error of 0.005 percent. An estimate of the error in the graphite content of the combustion residues can be derived from: (1) table 7 in which graphite blank experiments show an average deviation of $0.12 \mathrm{mg}$ and, (2) the average difference between the actual carbon contents found for the residues and the linearly weighted estimate of their carbon content, i.e., $0.23 \mathrm{mg}$. For this source of error we estimate 0.10 percent. On account of our inability to introduce a suitable correction for the amount of unburned Teflon present in the combustion residue without causing a significant spread in the graphite combustion data, we suggest an error of 0.10 percent. An error of about $8 \mathrm{~J}$ could be attributed to incomplete combustion of the tungsten fuse. This amounts to 0.02 percent for the Teflon and graphiteTeflon experiments. However, because the applied correction to the fuse energy would not be made in a random manner, we shall use half the suggested error ( $4 \mathrm{~J}$, or 0.01 percent) in calculating the overall experimental error. For errors incurred as a result of weighing samples, reaction prior to ignition, and bomb corrosion, we estimate 0.01 percent for each. From the determination of impurities in the graphite sample, we estimate a maximum error of 0.03 percent.

Estimates for errors incurred from the benzoic acid calibration experiments, Teflon combustion experiments, and combustion of the graphite-Teflon mixtures were made by multiplying the appropriate factor of the Student $t$ distribution at the 95 percent confidence level by the percent uncertainty in the scatter of the heat measurements. This latter uncertainty was found by dividing the calculated standard deviation of the mean for a particular set of measurement by its average value.

The total percent error for a given sample was found by taking the square root of the sum of the squares of the individual errors cited. The last entry gives the same total error expressed in kcal $\mathrm{mol}^{-1}$ for the respective heat of combustion.

\section{The Heats of Formation of Teflon, $\mathrm{CF}_{4}(\mathrm{~g})$ and $\operatorname{AlF}_{3}(\mathbf{c})$}

The calculated enthalpies of combustion at $298{ }^{\circ} \mathrm{K}$ for "Teflon 5" and "Teflon 7" are listed in tables 4 and 5 as $-10,368.3 \pm 0.9 \mathrm{~J} \mathrm{~g}^{-1}$ and $-10,369.4 \pm 0.8$ $\mathrm{J} \mathrm{g}^{-1}$, respectively. The cited uncertainties are the standard deviations of the means. These enthalpy values, which were not corrected for unburned residues, were appropriate for use in the calculation of the energy of combustion of graphite (and other substances to be reported later) burned as pelleted mixtures with Teflon. Inasmuch as we have data available on the analyses of Teflon combustion residues, we have calculated a corrected heat of combustion of Teflon in fluorine for the case of complete combustion. Using $0.10 \mathrm{mg}$ for the average amount of carbon found in a residue for an experiment after adjustment for a carbon blank of $0.04 \mathrm{mg}$, we estimate $0.24 \mathrm{mg}$ as the amount of unburned Teflon. Applying this figure to the average of all the experiments in tables 4 and 5 , we find for the corrected enthalpy of combustion 
of Teflon in fluorine (reaction (1)), $\Delta H_{298}^{\circ}=-10,371.3$ $\pm 3.1 \mathrm{~J} \mathrm{~g}^{-1}\left(-247.92 \pm 0.07 \mathrm{kcal} \mathrm{mol}^{-1}\right)$. The uncertainty cited is the overall experimental error calculated in table 10 .

$$
\mathrm{C}_{2} \mathrm{~F}_{4} \text { (solid polymer) }+2 \mathrm{~F}_{2}(\mathrm{~g})=2 \mathrm{CF}_{4}(\mathrm{~g})
$$

On the basis of our heat measurements of graphiteTeflon mixtures summarized in table 6 , the enthalpy of formation of $\mathrm{CF}_{4}(\mathrm{~g})$ (reaction (2)) is $-77,634.4 \mathrm{~J} \mathrm{~g}^{-1}$ $\left(-222.87 \mathrm{kcal} \mathrm{mol}^{-1}\right)$.

$$
\mathrm{C}(\mathrm{c}, \text { graphite })+2 \mathrm{~F}_{2}(\mathrm{~g})=\mathrm{CF}_{4}(\mathrm{~g}) \text {. }
$$

We estimate the overall experimental error for the direct combination of the elements to be $132.0 \mathrm{~J} \mathrm{~g}^{-1}$ $\left(0.38 \mathrm{kcal} \mathrm{mol}^{-1}\right)$.

Combining our measurements for the enthalpy changes of reactions (1) and (2), we calculate the heat of formation of polytetrafluoroethylene (Teflon) to be $-197.82 \pm 0.39 \mathrm{kcal}\left(\mathrm{gfw} \mathrm{C}_{2} \mathrm{~F}_{4}\right)^{-1}$.

An attempt to extrapolate the energy equivalent discussed under section 6.0 to the energy equivalent previously used [18] in determining the heat of formation of aluminum fluoride has been unsuccessful. However, because of the consistency of the present calibration data and heat of combustion data on "Teflon 5" over a three year period on samples from the same batch as was previously used, we feel the presently cited value of $-10,368.3 \mathrm{~J} \mathrm{~g}^{-1}$ in table 4 for the heat of combustion of "Teflon 5" is more accurate than our previously reported value, $-10,350.7$ $\mathrm{J} \mathrm{g}^{-1}$ [18]. Similarly, we feel that an adjustment of the heat of formation of aluminum fluoride by the factor $10,368.3 / 10,350.7$ is warranted giving a value $0.61 \mathrm{kcal} \mathrm{mol}^{-1}$ more negative than our previously reported valued [18]. We recommend for $\Delta H_{f 298}^{\circ}$ $\left[\mathrm{AlF}_{3}(\mathrm{c})\right],-361.0 \mathrm{kcal} \mathrm{mol}^{-1}$.

For the sake of consistency the value calculated in our previous paper [18] for $\Delta H_{f 298}^{\circ}\left[\mathrm{CF}_{4}(\mathrm{~g})\right]$ based on the heat of combustion of Teflon would now be -222.0 $\mathrm{kcal} \mathrm{mol}{ }^{-1}$ rather than $-221.8 \mathrm{kcal} \mathrm{mol}^{-1}$. However, this calculation is considered to be less informative than the treatment of the data given in section 10 .

\section{A Review of the Heat of Formation of Tetrafluoromethane}

In section 1 of this paper, we have cited without comment the values other investigators have reported for the heat of formation of $\mathrm{CF}_{4}(\mathrm{~g})$. Now, as a result of reporting our data on $\mathrm{CF}_{4}(\mathrm{~g})$, we wish to provide an evaluative comparison of our work to that of others. Because of the current uncertainty with regard to the heat of formation of $\mathrm{HF}$, the work to be discussed has been divided into two groups. First, we have examined reactions in which the heat of formation of $\mathrm{CF}_{4}(\mathrm{~g})$ does not directly involve the heat of formation of $\mathrm{HF}(\mathrm{g})$ or $\mathrm{HF}(\mathrm{aq})$, and have calculated values of $\Delta H_{f 298}^{\circ}\left[\mathrm{CF}_{4}(\mathrm{~g})\right]$ for the purpose of comparing them to our present work. Second, we have used our value for
$\Delta H_{f 298}^{\circ}\left[\mathrm{CF}_{4}(\mathrm{~g})\right]$ to calculate the heat of formation of $\mathrm{HF}(\mathrm{aq})$ at several concentrations, and have tried to explain why the derived data differs from other recently suggested values.

In table 11, we have summarized various thermochemical studies involving carbon tetrafluoride and shall refer to them during our examination of the reactions cited.

The work of von Wartenberg and Schütte [1] on the reaction of carbon with fluorine (table 11, reaction (1)) showed no control over the amount of higher fluorocarbons formed in the reaction or their subsequent analysis. In addition, the residual ash (containing some $\mathrm{CaF}_{2}$ ) also contained unspecified amounts of unburned material which the authors presumed to be carbon. An adjustment of $2.4 \mathrm{kcal} \mathrm{mol}^{-1}$ for the measured heat of formation of Norite was applied to the heat of combustion of Norite in fluorine, - $165 \pm 1.5$ kcal mol-1. This gave for the heat of formation of $\mathrm{CF}_{4}(\mathrm{~g}),-162.6 \mathrm{kcal}^{\mathrm{mol}^{-1}}$ which the authors apparently rounded to -162 , increasing the uncertainty to $2 \mathrm{kcal} \mathrm{mol}^{-1}$. The estimate by Ruff and Bretschneider [2] of the amount of fluorocarbons formed was still too small to bring the data close to the later determinations and causes us to feel the data of von Wartenberg and Schütte [1] should no longer be considered except for its historical interest.

Scott, Good, and Waddington [3, 4] reported burning Teflon in oxygen under a series of conditions which were extrapolated at one limit to the condition of no $\mathrm{HF}(\mathrm{aq})$ in the products (table 11 , reaction (2a)), and at the other limit to the condition in which no $\mathrm{CF}_{4}(\mathrm{~g})$ was formed (table 11 , reaction (2b)). Our reaction for the combustion of Teflon in fluorine appears in table 11 as reaction (3a), and combining it with reaction $(2 \mathrm{a})$, we obtain reaction $(3 \mathrm{c})$. For reaction $(3 \mathrm{c})$, we find $\Delta H_{298}^{\circ}=-129.12 \mathrm{kcal} \mathrm{mol}^{-1}$, which, when combined with $\Delta H_{f 298}^{\circ}\left[\mathrm{CO}_{2}(\mathrm{~g})\right]$, taken from Wagman et al. [21], to be $-94.051 \mathrm{kcal} \mathrm{mol}^{-1}$, gives for $\Delta H_{f 298}^{\circ}\left[\mathrm{CF}_{4}(\mathrm{~g})\right]$, $-223.17 \mathrm{kcal} \mathrm{mol}^{-1}$. This differs by $0.30 \mathrm{kcal} \mathrm{mol}^{-1}$ from our direct determination, an amount comparable to our overall experimental uncertainty.

Because this treatment of our data and that of Scott, Good, and Waddington does not involve HF in any way, we feel that it avoids the ambiguity that would be introduced by the uncertainty in the heat of formation of HF. For this reason we consider it to lead to more definite information about the heat of formation of $\mathrm{CF}_{4}(\mathrm{~g})$ than did our previous treatment [18].

Reactions involving $\mathrm{CF}_{4}(\mathrm{~g})$ and $\mathrm{NaF}(\mathrm{c})$ or $\mathrm{KF}(\mathrm{c})$ were carried out by von Wartenberg [7, 8], Kirkbride and Davidson [6], and Vorob'ev and Skuratov [10]. These reactions are listed as reactions (5) and (6) in table 11.

The carbonaceous product of the reaction of sodium with $\mathrm{CF}_{4}(\mathrm{~g})$ in the work of Vorob'ev and Skuratov [10] was identified by x-ray analysis as $\beta$-graphite and no correction was applied for its heat of formation. In a similar study by von Wartenberg $[7,8]$ the carbon was tested by combustion and x-ray methods, and, likewise, no correction was applied for the heat of formation of the product. However, in the case of 


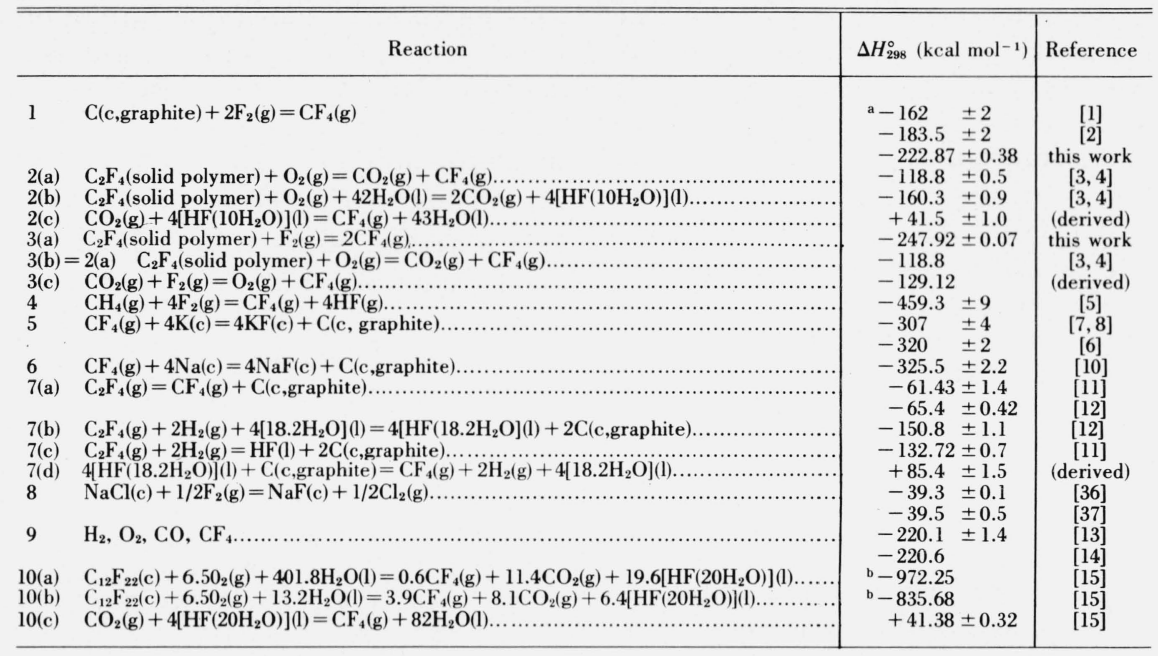

a Uncertainties listed are those given by the original authors, and are not necessarily comparable.

b $\Delta E_{298}^{\circ}\left(\mathrm{kcal} \mathrm{mol}^{-1}\right)$.

Kirkbride and Davidson [6], a correction of 2.5 kcal $\mathrm{mol}^{-1}$ was assumed for the heat of formation of the carbon formed based on their x-ray analysis of the carbon product. In the study by Neugebauer and Margrave [12] on the decomposition and reduction of $\mathrm{C}_{2} \mathrm{~F}_{4}(\mathrm{~g})$ shown in table 11 as reactions $(7 \mathrm{a})$ and (7b), finely divided soot was obtained for which they determined heats of formation of 1.5 and $1.9 \mathrm{kcal}$ $\mathrm{mol}^{-1}$, respectively. In the early combustion study of von Wartenberg and Schütte [1] in which the sample was activated charcoal (Norite), a correction of $2.4 \mathrm{kcal} \mathrm{mol}^{-1}$ was applied in the calculations for the heat of formation of the Norite based upon combustion measurements. Evidence that the carbon obtained by Vorob'ev and Skuratov [10] was actually an active form is found in their statement that they observed an exothermic post-reaction process which they attributed to the absorption of $\mathrm{CF}_{4}$ by the carbon. They did not include this heat in their calculation or make any correction based upon it. In a later publication involving $\mathrm{Na}(\mathrm{c})$ and $\mathrm{C}_{2} \mathrm{~F}_{4}(\mathrm{~g})$, however, Kolesov, Zenkov, and Skuratov [35] found amorphous carbon among the products. They measured its heat of combustion from which they calculated a heat of formation of $3.95 \mathrm{kcal} \mathrm{mol}^{-1}$.

The possibility of a rather large range of positive heats of formation of the finely divided carbon formed in reactions (5) and (6) is a major source of uncertainty in the interpretation of the experimental results. We shall return to this point later.

The heat of formation of $\mathrm{CF}_{4}(\mathrm{~g})$ can be calculated from reactions (5) and (6) using heat of formation data on $\mathrm{NaF}(\mathrm{c})$ or $\mathrm{KF}(\mathrm{c})$ as has been done by the aforementioned investigators $[6,7,8,10]$ or as is illustrated in the JANAF Thermochemical Tables [28] and the review by Cox, Gundry, and Head [15]. However, if we wish to circumvent the dependence upon the heat of formation of $\mathrm{HF}$, there are available two heat measurements on a reaction (table 11 , reaction 8) not involving $\mathrm{HF}$ which we can use to calculate the heat of for- mation of sodium fluoride. The measurements of von Wartenberg and Fitzner [36] and of Schmitz and Schumaker [37] are in good agreement with each other and require only the heat of formation of $\mathrm{NaCl}(\mathrm{c})$ to permit calculation of the heat of formation of $\mathrm{NaF}(\mathrm{c})$. Using $\Delta H_{f 298}^{\circ}[\mathrm{NaCl}(\mathrm{c})]=-98.232 \mathrm{kcal} \mathrm{mol}^{-1}[16]$, we obtain for $\Delta H_{f 298}^{\circ}[\mathrm{NaF}(\mathrm{c})],-137.5 \mathrm{kcal} \mathrm{mol}^{-1}$ from the work of von Wartenberg and Fitzner, and - 137.7 kcal mol-1 from the work of Schmitz and Schumaker. Applying these results to reaction (6) of table 11, for which the reaction was measured by Vorob'ev and Skuratov, we calculate $\Delta H_{f 298}^{\circ}\left[\mathrm{CF}_{4}(\mathrm{~g})\right]=-224.5$ and $-225.3 \mathrm{kcal} \mathrm{mol}^{-1}$, respectively. The average of these is more negative by about $2 \mathrm{kcal} \mathrm{mol}^{-1}$ than our reported value.

We have not found a concise reaction scheme by which the heat of formation of $\mathrm{KF}(\mathrm{c})$ can be obtained without reference to HF. However, if we presume that the heats of formation of $\mathrm{NaF}(\mathrm{c})$ and $\mathrm{KF}(\mathrm{c})$ bear the proper relationship to one another in NBS Circular 500 [16], $\left(\Delta H_{f 298}^{\circ}[\mathrm{NaF}(\mathrm{c})]-\Delta H_{f 298}^{\circ} \mathrm{KF}(\mathrm{c})\right]=-136.0$ $+134.46=-1.54 \mathrm{kcal} \mathrm{mol}^{-1}$ ), the most negative value attributable to $\Delta H_{f 298}^{\circ}[\mathrm{KF}(\mathrm{c})]$ would be $-136.16 \mathrm{kcal}$ $\mathrm{mol}^{-1}$ on the basis of the previous discussion of $\mathrm{NaF}(\mathrm{c})$. If we apply this information to reaction (5) and the data of Kirkbride and Davidson [6], we find $\Delta H_{f 298}^{\circ}\left[\mathrm{CF}_{4}(\mathrm{~g})\right] \leqslant-224.6 \mathrm{kcal} \mathrm{mol}^{-1}$. However, here we must bear in mind that the latter authors applied an arbitrary correction for the heat of formation of amorphous carbon of $2.5 \mathrm{kcal} \mathrm{mol}^{-1}$, which may be too large by $1.0 \mathrm{kcal} \mathrm{mol}^{-1}$ or too small by $1.5 \mathrm{kcal} \mathrm{mol}^{-1}$ on the basis of reported measurements of the heat of formation of amorphous carbon found in other laboratories. The work of von Wartenberg [7, 8] seems to be so far from the other studies that we shall not attempt to reconcile it with them.

The values calculated above for $\Delta H_{f 298}^{\circ}\left[\dot{C F}_{4}(\mathrm{~g})\right]$ on the basis of reactions involving $\mathrm{KF}(\mathrm{c})$ or $\mathrm{NaF}(\mathrm{c})$ are subject to two sources of uncertainty. Some ClF 
may have formed in the reaction of $\mathrm{NaCl}$ with fluorine (reaction 8). If so the observed heats of formation of $\mathrm{NaF}(\mathrm{c})$ and, hence of $\mathrm{CF}_{4}(\mathrm{~g})$ would be less negative as the result of adjusting for the formation of ClF. In addition, if the carbon formed in the experiments had a positive heat of formation, as seems quite plausible on the basis of the foregoing discussion, the values calculated for $\Delta H_{f 298}^{\circ}\left[\mathrm{CF}_{4}(\mathrm{~g})\right]$ would have to be adjusted to less negative values in all experiments except possibly those of Kirkbride and Davidson [6].

As a result of applying such corrections to the work of Kirkbride and Davidson [6] and Vorob'ev and Skuratov [10], the values calculated for $\Delta H_{f 298}^{\circ}\left[\mathrm{CF}_{4}(\mathrm{~g})\right]$ could both become less negative than the value found in our work.

The fact that Kirkbride and Davidson [6] and Vorob'ev and Skuratov [10] did not measure the heat of combustion of the carbon which was formed in their experiments has reduced the ultimate usefulness of their measurements on $\mathrm{CF}_{4}$ since there seems to be no way to relate their measurements clearly to a well-defined standard state of carbon.

We have not attempted any evaluative comparison between the work of Baibuz [13] and Baibuz and Medvedev [14] and our own since the former is not available in sufficient detail for us to perform any recalculations.

In summarizing the review of work on the heat of formation of $\mathrm{CF}_{4}$ that is independent of the heat of formation of $\mathrm{HF}$, we find that the values as calculated from the reaction of graphite with fluorine, and from the reactions of Teflon with fluorine and oxygen are in good agreement, indicating the accuracy of the results presented in this paper. The values which can be derived from other reactions not involving HF are consistent with our data, but allow a range of values which bracket our data.

We have examined certain reactions which involve both $\mathrm{CF}_{4}(\mathrm{~g})$ and $\mathrm{HF}(\mathrm{g})$ or $\mathrm{HF}(\mathrm{aq})$, and as a result of applying our data on the enthalpy of formation of $\mathrm{CF}_{4}(\mathrm{~g})$, have been able to calculate values for $\Delta H_{f 298}^{\circ}[\mathrm{HF}(\mathrm{aq})]$ at several concentrations.

The work of Jessup, McCoskey, and Nelson [5] on the gas phase combustion of methane in fluorine (table 11, reaction (4)) consisted of three measurements and led to a heat of reaction of $-459.3 \mathrm{kcal}$ $\mathrm{mol}^{-1}$. Included in the overall experimental error was a correction for the nonideality of $\mathrm{HF}$ of 1.5 to $2.0 \mathrm{kcal} \mathrm{mol}^{-1}$. Since these latter authors estimated the accuracy of their work at about \pm 2 percent, we doubted whether further calculation or extrapolation of their work using our data on $\mathrm{CF}_{4}(\mathrm{~g})$ was useful, and, therefore, have not considered these results any further.

The decomposition of $\mathrm{C}_{2} \mathrm{~F}_{4}(\mathrm{~g})$ into $\mathrm{CF}_{4}(\mathrm{~g})$ and carbon, and the hydrogenation of $\mathrm{C}_{2} \mathrm{~F}_{4}(\mathrm{~g})$ were carried out by Duus [11] and Neugebauer and Margrave [12]. The latter authors remedied several of the experimental difficulties of Duus. They determined the heat of formation of the carbon formed in the reactions and in the hydrogenation of $\mathrm{C}_{2} \mathrm{~F}_{4}(\mathrm{~g})$, they caused the hydrogen fluoride produced to be dissolved in water avoiding the problem of large and uncertain corrections for the amount of HF present as the gas phase. Reactions $7 \mathrm{a}$ and $7 \mathrm{~b}$ of table 11 can be combined to eliminate $\mathrm{C}_{2} \mathrm{~F}_{4}(\mathrm{~g})$ which is common to both. For the resulting reaction (reaction $7 \mathrm{~d}$ ), the work of Neugebauer and Margrave was used in preference to that of Duus, and gave $\Delta H_{298}^{\circ}=85.4 \mathrm{kcal} \mathrm{mol}^{-1}$. Applying our value, $\Delta H_{f 298}^{\circ}\left[\mathrm{CF}_{4}(\mathrm{~g})\right]=-222.87 \mathrm{kcal} \mathrm{mol}^{-1}$ to this reaction led to $\Delta H_{f 298}^{\circ}\left[\mathrm{HF}\left(18.2 \mathrm{H}_{2} \mathrm{O}\right)(\mathrm{aq})\right]=-77.07$ $\pm 0.4 \mathrm{kcal} \mathrm{mol}^{-1}$.

The work of Good, Scott, and Waddington [3, 4] on the combustion of Teflon in oxygen is illustrated in table 11 as reactions $(2 \mathrm{a})$ and $(2 \mathrm{~b})$. Elimination of Teflon from these reactions by subtraction leads to reaction (2c) for which their measurements give 41.5 $\mathrm{kcal} \mathrm{mol}{ }^{-1}$. Applying heat of formation values for $\mathrm{CO}_{2}(\mathrm{~g}), \mathrm{H}_{2} \mathrm{O}(\mathrm{l})$ and $\mathrm{CF}_{4}(\mathrm{~g})$ of $-94.051,-68.315$ and $-222.87 \mathrm{kcal} \mathrm{mol}^{-1}$, respectively, we calculate for $\Delta H_{f 298}^{\circ}\left[\mathrm{HF}\left(10 \mathrm{H}_{2} \mathrm{O}\right)(\mathrm{aq})\right],-76.74 \pm 0.35 \mathrm{kcal} \mathrm{mol}^{-1}$.

Cox, Gundry, and Head [15] measured the heat of combustion of docosafluorobicyclohexyl in oxygen under a similar range of conditions to that used by Good, Scott, and Waddington $[3,4]$ on Teflon. The limits of the extrapolation led them to reactions (10a) and $(10 \mathrm{~b})$ in table 11 from which reaction (10c) is obtained by difference. For reaction (10c) they obtained $41.38 \pm 0.32 \mathrm{kcal} \mathrm{mol}^{-1}$. Applying the same auxiliary data as above, we calculate $\Delta H_{f 298}^{\circ}\left[\mathrm{HF}\left(20 \mathrm{H}_{2} \mathrm{O}\right)\right.$ $(\mathrm{aq})]=-76.71 \pm 0.2 \mathrm{kcal} \mathrm{mol}^{-1}$.

The values obtained above for the enthalpies of formation of $\mathrm{HF}(\mathrm{aq})$ at three concentrations are shown in table 12. The values suggested by Cox and Harrop [17] and Wagman et al. [21], are compared to $\Delta H_{f 298}^{\circ}$ values calculated using our $\Delta H_{f 298}^{\circ}$ on $\mathrm{CF}_{4}(\mathrm{~g})$. The values in parentheses represent the differences between values shown in successive rows in $\mathrm{kcal} \mathrm{mol}^{-1}$. The work of Cox and Harrop [17] is based upon a new determination of the heat of solution of $\mathrm{HF}(\mathrm{g})$ combined with the value $\Delta H_{f 298}^{\circ}[\mathrm{HF}(\mathrm{g})]=-64.92 \mathrm{kcal}$ $\mathrm{mol}^{-1}$ [38]. The survey of Wagman et al. [21], is based upon older work, but uses the value $\Delta H_{f 298}^{\circ}[\mathrm{HF}(\mathrm{g})]$ $=-64.8 \mathrm{kcal} \mathrm{mol}^{-1}$.

We wish to point out that the heat of formation data calculated for HF solutions in table 12 are each internally consistent with respect to the three sources and show differences from one another that are constant at least within the uncertainties of the three measurements upon which our calculated heat of formation values for $\mathrm{HF}(\mathrm{aq})$ are based. Secondly, our calculated values are 0.3 to $0.7 \mathrm{kcal} \mathrm{mol}^{-1}$ less negative than those of Cox and Harrop [17], and are 0.4 to $0.8 \mathrm{kcal} \mathrm{mol}^{-1}$ more negative than those of Wagman et al. [21].

TABLE 12. Comparison of some reported values for $\Delta \mathrm{H}_{f 298}^{\circ}\left[\mathrm{HF}\left(\mathrm{nH}_{2} \mathrm{O}\right)(\mathrm{aq})\right]$

\begin{tabular}{|c|c|c|c|}
\hline$\left[\mathrm{HF}\left(n \mathrm{H}_{2} \mathrm{O}\right)(\mathrm{aq})\right]$ & $10 \mathrm{H}_{2} \mathrm{O}$ & $18.2 \mathrm{H}_{2} \mathrm{O}$ & $20 \mathrm{H}_{2} \mathrm{O}$ \\
\hline $\begin{array}{l}\text { Cox and Harrop [17]... } \\
\text { This work............... } \\
\text { Wagman et al. [21]..... }\end{array}$ & $\begin{array}{c}-77.367 \mathrm{kcal} \mathrm{mol}^{-1} \\
(0.63) \\
-76.74 \mathrm{kcal} \mathrm{mol} \\
(0.51) \\
-76.235 \mathrm{kcal} \mathrm{mol}^{-1}\end{array}$ & $\begin{array}{c}-77.391 \mathrm{kcal} \mathrm{mol}^{-1} \\
(0.32) \\
-77.07 \mathrm{kcal} \mathrm{mol}-1 \\
(0.79) \\
-76.279 \mathrm{kcal} \mathrm{mol}^{-1}\end{array}$ & $\begin{array}{l}-77.396 \mathrm{kcal} \mathrm{mol}^{-1} \\
(0.69) \\
-76.71 \mathrm{kcal} \mathrm{mol} \mathrm{mol}^{-1} \\
(0.43) \\
-76.283 \mathrm{kcal} \mathrm{mol} \mathrm{mol}^{-1}\end{array}$ \\
\hline
\end{tabular}


To account for the differences observed, several possibilities present themselves. First, our heat of formation data on $\mathrm{CF}_{4}(\mathrm{~g})$ could be in error. To bring our data in line with either that of Cox and Harrop or Wagman et al., would require that our enthalpy of formation for $\mathrm{CF}_{4}(\mathrm{~g})$ be more negative or more positive by 1.3 to $3.2 \mathrm{kcal} \mathrm{mol}^{-1}$. This large an error in our data is difficult to envision. Secondly, the calorimetric work of Cox and Harrop seems to have no possible source of error as large as what we are looking for. The choice of the heat of formation of $\mathrm{HF}(\mathrm{g})$ could possibly be in error. They chose -64.92 kcal mol-1 as the value for $\Delta H_{f 298}^{\circ}[\mathrm{HF}(\mathrm{g})]$. This value was suggested by Feder et al. [38], on the basis of reactions involving the fluorination of $\mathrm{SiO}_{2}$ and the hydrolysis of $\mathrm{SiF}_{4}$. Agreement between our data and that of Cox and Harrop could be attained if a $\Delta H_{f 298}^{\circ}$ value for $\mathrm{HF}(\mathrm{g})$ of -64.3 to $-64.6 \mathrm{kcal} \mathrm{mol}^{-1}$ were used.

An error could be present in the heat of vaporization of $\mathrm{HF}(\mathrm{g})$ from $\mathrm{LiHF}_{2}$ (c) which was determined from vapor pressure measurements, and entropy data on $\mathrm{LiHF}_{2}(\mathrm{c}), \mathrm{LiF}(\mathrm{c})$ and $\mathrm{HF}(\mathrm{g})$. Because hydrogen fluoride, vaporizing from $\mathrm{LiHF}_{2}$ will come from within the lattice, a porous structure is formed when the process occurs. If the resulting solid has a high free energy relative to the bulk crystal, the free energy of vaporization will be greater than for the process leaving $\mathrm{LiF}$ in the standard state. The vapor pressure in this case would be lower than the equilibrium value. Some evidence for this type of behavior has been observed with the decomposition of $\mathrm{NaHF}_{2}$. However, the necessary reduction in pressure is approximately a factor of two to account for the observed energy error. This factor is improbably large.

If crystalline $\mathrm{LiHF}_{2}$ has an entropy equal to $R \ln 2$ at the absolute zero, a contribution of $1.377 \mathrm{cal} \mathrm{deg}^{-1}$ $\mathrm{mol}^{-1}$ would be added to the entropy of dissociation of $\mathrm{LiHF}_{2}(\mathrm{c})$, or a contribution of about $-0.4 \mathrm{kcal} \mathrm{mol}^{-1}$ to the enthalpy of dissociation. These heat data are part of the cycle used by Cox and Harrop to calculate the heats of formation of aqueous HF solutions, and would bring our data on $\Delta H_{f 298}^{\circ}[\mathrm{HF}(\mathrm{aq})]$ in table 12 into much better agreement with that of Cox and Harrop.

We may presume that as a simple substance in a cubic lattice, $\mathrm{LiF}$ will have $S_{0}^{\circ}=0$ and that for ideal-gas $\mathrm{HF}, S_{0}^{\circ}=0$. However, in $\mathrm{LiHF}_{2}$ (c) we find a much more complicated structure. In particular, the possibility of two equivalent positions for the hydrogen atom in the $\mathrm{HF}_{2}^{-}$ion should be considered. Two such equivalent positions would exist if there were a double minimum in the potential between two fluorine atoms.

The question of a double minimum in the bifluoride ion analogous to the double minimum in the potential between oxygen atoms in a hydrogen bonded substance has been repeatedly examined by Westrum and his co-workers [39-43] and others [44-50]. Little if any positive evidence has been found; yet, continuing work indicates lingering doubts about the circumstances under which the unsymmetrically lo- cated proton will occur. In particular, little evidence referring specifically to $\mathrm{LiHF}_{2}(\mathrm{c})$ has been presented except the crystal structure [51], which gives the $\mathrm{F}-\mathrm{F}$ bond distance, and a heat capacity and vapor pressure study by Westrum and Burney [42]. Unfortunately, the calorimetric and vapor pressure measurements of Westrum and Burney do not overlap with one another and cannot provide any information on the existence of a double minimum.

\section{References}

[1] H. von Wartenberg and R. Schütte, Z. Anorg. Chem. 211 , 222-6 (1933)

[2] O. Ruff and O. Bretschneider, Z. Anorg. Chem. 21 7, 19-21 (1934).

[3] D. W. Scott, W. D. Good, and G. Waddington, J. Am. Chem. Soc. 77, 245-6 (1955).

[4] W. D. Good, D. W. Scott, and G. Waddington, J. Phys. Chem. 60, 1080-9 (1956).

[5] R. S. Jessup, R. E. McCoskey, and R. A. Nelson, J. Am. Chem. Soc. 7 7, 244-5 (1955).

[6] F. W, Kirkbride and F. G. Davidson, Nature 1 74, 79-80 (1954).

[7] H. von Wartenberg, Nach. Ges. Wiss. Gottingen (Math Phys. Klasse), 57-8 (1946).

[8] H. von Wartenberg, Z. Anorg. Chem. 258, 356-60 (1949).

[9] H. von Wartenberg and J. Sčhiefer, Z. Anorg. u. Allgem. Chem. 278, 326-32 (1955).

[10] A. F. Vorob'ev and S. M. Skuratov, Zhur. Neorg. Khim. 5, 1398-1401 (1960); see also Russ. J. Inorg. Chem. 5, 679-681 (1960).

[11] H. C. Duus, Ind. Eng. Chem. 47, 1445-9 (1955).

[12] C. A. Neugebauer and J. L. Margrave, J. Phys. Chem. 60, 1318-21 (1956).

[13] V. F. Baibuz, Doklad. Akad. Nauk S.S.S.R. 140, 1358-60 (1961).

[14] V. F. Baibuz and V. A. Medvedev, Tr. Gos. Inst. Prikl. Khim. No. 49, 84-112 (1962).

[15] J. D. Cox, H. A. Gundry, and A. J. Head, Trans. Faraday Soc. 61, 1594-1600 (1965).

[16] F. D. Rossini, D. D. Wagman, W. H. Evans, S. Levine, and I. Jaffe, Selected Values of Chemical Thermodynamic Properties, NBS Circular 500 (U.S. Government Printing Office, Washington, D.C., 1952).

[17] J. D. Cox and D. Harrop, Trans. Faraday Soc. 61, 1328-37 (1965).

[18] E. S. Domalski and G. T. Armstrong, J. Res. NBS 69A (Phys. and Chem.) No. 2, 137-47 (1965).

[19] O. Kubaschewsky and E. Ll. Evans, Metallurgical Thermochemistry, 3d edition (John Wiley \& Sons, Inc., New York, 1958).

[20] G. N. Lewis and M. Randall, K. S. Pitzer and L. Brewer, Thermodynamics, 2d edition (McGraw-Hill Book Co., New York, N.Y., 1961).

[21] D. D. Wagman, W. H. Evans, I. Halow, V. B. Parker, S. M Bailey, and R. H. Schumm, NBS Technical Note 270-1, October 1, 1965.

[22] Powder Diffraction File, ASTM card 12-212, Philadelphia, $\mathrm{Pa}$; data by M. H. Reed, Bell Telephone Labs., Murray Hill, N.J. (1960).

[23] G. T. Armstrong and R. S. Jessup, J. Res. NBS 64A (Phys. and Chem.) No. 1, 49-59 (1960).

[24] R. P. Rossman and W. R. Smith, Ind. Eng. Chem. 35, 972-6 (1943).

[25] O. E. Myers and A. P. Brady, J. Phys. Chem. 64, 591-4 (1960).

[26] W. H. Evans, NBS, private communication, July 1, 1960.

[27] W. H. Evans, J. Hilsenrath, and H. W. Woolley, NBS, private communication, July 1, 1960.

[28] Dow Chemical Company, JANAF Thermochemical Tables, PB 168370 (Clearinghouse for Federal Scientific and Technical Information, Springfield, Virginia, 1965).

[29] W. N. Hubbard. Fluorine Bomb Calorimetry, Chapter 6, Ex perimental Thermochemistry, Vol. II, H. A. Skinner, ed. (Interscience Publishers, Inc., New York, 1962). 
[30] J. O. Hirschfelder, C. F. Curtiss, and R. B. Bird, Molecular Theory of Gases and Liquids (John Wiley \& Sons, Inc., New York, N.Y., 1954, Second Printing, 1964).

[31] D. White, H. Hu, and H. L. Johnston, J. Chem. Phys. 24, 1149-52 (1953)

[32] D. R. Douslin, paper No. 11, pp. 135-46, PVT Relations and Intermolecular Potentials for Methane and Carbon Tetrafluoride in Progress in International Research on Thermodynamics and Transport Properties, J. F. Masi and D. H. Tsai, editors, (Academic Press, New York, 1962).

[33] A. E. Cameron and E. Wichers, J. Am. Chem. Soc. 84, 4175-97 (1962).

[34] C. H. Shomate, Computer Calculations of Combustion Bomb Calorimetric Data, Technical Progress Report 327, NOTS TP 3288, U.S. Naval Ordnance Test Station, China Lake, California, August, 1963.

[35] V. P. Kolesov, I. D. Zenkov, and S. M. Skuratov, Zhur. Fiz. Khim. 36, 89-92 (1962); see also Russ. J. Phys. Chem. 36, 45-7 (1962).

[36] H. von Wartenberg and O. Fitzner, Z. Anorg. u. Allgem. Chem. 151, 313-25 (1926)

[37] H. Schmitz and H. J. Schumacher, Z. Naturforsch, 2A, 362 (1947).

[38] H. M. Feder, W. N. Hubbard, S. S. Wise, and J. L. Margrave, J. Phys. Chem. 67, 1148-50 (1963).
[39] K. S. Pitzer and E. F. Westrum, Jr., J. Chem. Phys. 15, 526 (1947).

[40] E. F. Westrum, Jr. and K. S. Pitzer, J. Am. Chem. Soc. 71. 1940-48 (1949).

[41] M. L. Davis and E. F. Westrum, Jr., J. Phys. Chem. 65, 338-344 (1961).

[42] E. F. Westrum, Jr., and G. A. Burney, J. Phys. Chem. 65, 344-8 (1961).

[43] T. L. Higgins and E. F. Westrum, Jr., J. Phys. Chem. 65, 830-6 (1961).

[44] R. Blinc, Z. Trontelj, and B. Volavesk, J. Chem. Phys. 44, 1028-33 (1966).

[45] J. D. Forrester, M. E. Senko, A. Zalkin, and D. H. Templeton, Acta Cryst. 16, 58-62 (1963).

[46] S. W. Peterson and H. A. Levy, J. Chem. Phys. 20, 704-7 (1952).

[47] L. Pauling, J. Am. Chem. Soc. 57, 2680-4 (1935).

[48] J. A. Ibers, J. Chem. Phys. 40, 402-4 (1964).

[49] B. L. Megaw and J. A. Ibers, J. Chem. Phys. 39, 2677-2684 (1963).

[50] J. A. A. Katelaar and W. Vedder, J. Chem. Phys. 19, 654 (1951).

[51] L. K. Frevel and H. W. Rinn, Acta-Cryst. 15, 286 (1962).

(Paper 71A2-440) 